\title{
FOLFIRI as a second-line therapy in patients with docetaxel-pretreated gastric cancer: a historical cohort
}

\author{
Marcello Maugeri-Saccà ${ }^{1,2^{*}}$, Laura Pizzuti ${ }^{1}$, Domenico Sergi ${ }^{1}$, Maddalena Barba ${ }^{1}$, Franca Belli ${ }^{3}$, \\ Silvia lleana Fattoruso ${ }^{4}$, Diana Giannarelli ${ }^{5}$, Antonella Amodio ${ }^{1}$, Sara Boggia ${ }^{6}$, Patrizia Vici ${ }^{1}$ and Luigi Di Lauro ${ }^{1}$
}

\begin{abstract}
Background: The role of second-line therapy in gastric cancer patients mostly stemmed from clinical trials with monochemotherapy carried out in Asian countries. Nevertheless, these results cannot be broadly generalized as molecular studies suggested the existence of different sets of deregulated gene networks correlated with ethnicity. In the present study, we investigated the activity and safety of FOLFIRI given as a second-line therapy in metastatic gastric or gastro-esophageal junction cancer patients who experienced disease progression on or after first-line docetaxel-containing chemotherapy.
\end{abstract}

Methods: Patients with histologically confirmed metastatic gastric cancer who failed docetaxel-containing first-line therapy and who received FOLFIRI in second line were eligible for the study. Seventy patients treated at three Italian cancer centers between 2005 and 2012 entered the study. Patients received every 2 weeks irinotecan $180 \mathrm{mg} / \mathrm{m}^{2}$ as $1 \mathrm{~h}$ infusion on day 1 , folinic acid $100 \mathrm{mg} / \mathrm{m}^{2}$ intravenously days $1-2$, and fluorouracil as a $400 \mathrm{mg} / \mathrm{m}^{2}$ bolus and then $600 \mathrm{mg} / \mathrm{m}^{2}$ continuous infusion over 22 hours days $1-2$.

Results: We observed 1(1.4\%) complete response, 15 (21.4\%) partial response, for an overall response rate of 22.8\% (95\% confidence interval (Cl): 13.4-32.3). Stable disease was recorded in 21 (30\%) patients. Median progression-free survival and overall survival were 3.8 months (95\% Cl: 3.3-4.4) and 6.2 months ( $95 \%$ Cl: 5.3-7.1), respectively. The treatment was well tolerated, as the most common G3-4 toxicities were neutropenia (28.5\%) and diarrhea (14.5\%).

Conclusions: FOLFIRI appears an effective and safe treatment option for pretreated metastatic gastric cancer patients, and deserves further investigation in randomized clinical trials.

Keywords: FOLFIRI, Gastric cancer, Second-line chemotherapy

\section{Background}

Gastric cancer and cancer of the gastro-oesophageal junction (GEJ) are a significant global health problem, representing the fourth most common cancer diagnosed worldwide [1]. The prognosis for these patients remain poor, as the majority of them are diagnosed with locally advanced or metastatic disease with a median survival of 7-10 months [2].

\footnotetext{
* Correspondence: maugeri.marcello@gmail.com

'Division of Medical Oncology B, "Regina Elena" National Cancer Institute, Via Elio Chianesi, 5300144 Rome, Italy

${ }^{2}$ Scientific Direction, "Regina Elena" National Cancer Institute, Via Elio Chianesi, 5300144 Rome, Italy

Full list of author information is available at the end of the article
}

Several randomized clinical trials demonstrated the role of chemotherapy in the first-line setting, as different regimens determined an improvement in survival and in quality of life (QoL) compared with best supportive care (BSC) alone [3-5]. More recently, a wave of randomized clinical trials with superiority design was successfully completed, and novel active drugs such as docetaxel [6], S1 [7] and trastuzumab [8] changed the landscape of the clinical management of gastric cancer. Other agents including capecitabine [9], oxaliplatin [10] and irinotecan [11] have proven antitumor activity, thus expanding the spectrum of therapeutic options available in the first-line setting. Even though novel active drugs and combinations entered the therapeutic scenario, second-line treatment

\section{() Biomed Central}


has been historically considered largely empirical. Furthermore, geographic distributions exist in chemotherapy administration beyond first-line, being prevalently adopted in Asian countries. Indeed, the rates of administration of subsequent chemotherapy significantly differed among phase III studies conducted in front-line, spanning from $14 \%$ in the UK REAL 2 study [9] to $75 \%$ in the Japanese SPIRITS trial [7].

The clinical proof-of-concept for second-line chemotherapy stemmed from two recent randomized phase III trials, demonstrating the superiority of second-line monotherapy (docetaxel or irinotecan) over BSC $[12,13]$. Nevertheless, it is foreseeable that a widespread adoption of second-line chemotherapy will further be limited by multiple factors. Firstly, the non-Asian study was prematurely closed when only one-third of the preplanned 120 patients were enrolled [12]. As a result, evidence supporting second-line chemotherapy in non-Asian patients are still scattered being mostly extrapolated from the Korean study. Secondly, the different biological background of gastric cancer arising in Asian and Western patients must be taken into account as a potential confounding factor [14]. Finally, single-agent therapy may result suboptimal, at least for patients with good performance status.

On this basis, we conducted a retrospective study in order to evaluate the activity and safety of FOLFIRI given as a second-line therapy in a cohort of docetaxelpretreated metastatic gastric cancer patients.

\section{Methods}

The study population was composed by patients with metastatic gastric or GEJ cancer who experienced disease progression on or after first-line docetaxel-containing chemotherapy. Patients were treated at three Italian cancer centers between 2005 and 2012. The majority of patients was selected from the "Regina Elena" National Cancer Institute, Rome. Medical records were reviewed in order to obtain information on demography, treatment received, safety and outcomes.

Patients with histologically confirmed, docetaxelpretreated metastatic gastric cancer who received FOLFIRI in second line were eligible for the study. Other eligibility criteria included Eastern Cooperative Oncology Group performance status $\leq 2$ (ECOG PS), aged between 18 and 75 years, adequate bone marrow (absolute neutrophil count $\geq 1500 / \mu \mathrm{l}$, platelet count $\geq 100000 / \mu \mathrm{l})$, renal (serum creatinine $\leq 1.5 \mathrm{mg} / \mathrm{dl}$ ) and liver (serum bilirubin $\leq 2 \mathrm{mg} / \mathrm{dL}$ ) functions, normal cardiac function, absence of second primary tumor other than non-melanoma skin cancer or in situ cervical carcinoma, no central nervous system involvement, no prior radiotherapy in target lesions, and no concurrent uncontrolled medical illness.
Patients received every 2 weeks irinotecan $180 \mathrm{mg} / \mathrm{m}^{2}$ as $1 \mathrm{~h}$ infusion on day 1 , folinic acid $100 \mathrm{mg} / \mathrm{m}^{2}$ intravenously days $1-2$, and fluorouracil as a $400 \mathrm{mg} / \mathrm{m}^{2}$ bolus and then $600 \mathrm{mg} / \mathrm{m}^{2}$ continuous infusion over 22 hours days $1-2$. The dose of irinotecan was reduced to $150 \mathrm{mg} / \mathrm{m}^{2}$ in patients older than 70 years. Chemotherapy was generally administered on an outpatient basis for a maximum of 12 cycles. Treatment was continued until disease progression or unacceptable toxicity.

Toxicity was graded according to the National Cancer Institute-Common Toxicity Criteria version 4.0 (NCICTC v. 4.0). Tumor response was evaluated according to the response evaluation criteria for solid tumors (RECIST 1.1). Progression-free survival (PFS) and overall survival (OS) were calculated from the date of therapy initiation to the date of disease progression, death from any cause or last follow-up evaluation, respectively. PFS and OS were analyzed according to the Kaplan-Meier method. The Cox proportional hazards regression model was used for univariate analysis of prognostic factors for survival. All statistical analyses were performed using SPSS statistical software version 20 (SPSS inc.,Chicago IL, USA). The study was approved by the coordinating centre's Ethics Committee at the "Regina Elena" National Cancer Institute, Rome, and was carried out according to the principles of the Declaration of Helsinki. A written informed consent was obtained from all patients.

\section{Results}

\section{Patients characteristics}

Seventy patients with a median age of 65 years (range, 32-75) were included in this study. Patients' characteristics are illustrated in Table 1 . The primary tumor site was stomach in 54 patients (77\%) and the GEJ in 16 patients (23\%). The histology subtype was diffuse, intestinal and unknown in 33 (47\%), 29 (41.5\%), and 8 (11.5) patients, respectively. Primary tumor resection was carried out in twenty-five patients (36\%). The ECOG PS was 0, 1 and 2 in 10 (14.5\%), 40 (57\%) and 20 (28.5\%) patients, respectively. Fifty-three patients $(76 \%)$ had two or more metastatic sites. PFS during first-line chemotherapy was $\geq$ 6 months in 42 patients (60\%), and the chemotherapy-free interval was $>3$ months in 38 patients (54\%). Among regimens administered in the first-line setting, 25 patients (36\%) received docetaxel, oxaliplatin and capecitabine [15], 20 patients $(28.5 \%)$ received epirubicin, cisplatin and docetaxel [16], 19 patients (27\%) were treated with epirubicin, oxaliplatin and docetaxel [17], and 6 patients $(8.5 \%)$ received cisplatin and docetaxel [18].

\section{Efficacy}

Response to treatment is illustrated in Table 2. Among 70 assessable patients, we observed $1(1.4 \%)$ complete response (CR), $15(21.4 \%)$ partial responses (PR), for an 
Table 1 Patient characteristics

\begin{tabular}{|c|c|c|}
\hline Characteristic & No. of patients & $\%$ \\
\hline Patients evaluable & 70 & 100 \\
\hline \multicolumn{3}{|l|}{ Age, years } \\
\hline Median (range) & $65(32-75)$ & \\
\hline \multicolumn{3}{|l|}{ Sex } \\
\hline Male & 41 & 58.5 \\
\hline Female & 29 & 41.5 \\
\hline \multicolumn{3}{|c|}{ Response to prior chemotherapy } \\
\hline Yes & 44 & 63 \\
\hline No & 26 & 37 \\
\hline \multicolumn{3}{|c|}{ Status of primary tumor } \\
\hline Resected & 25 & 36 \\
\hline Unresected & 45 & 64 \\
\hline \multicolumn{3}{|l|}{ Tumor histology } \\
\hline Diffuse & 33 & 47.2 \\
\hline Intestinal & 29 & 41.4 \\
\hline Unknown & 8 & 11.4 \\
\hline \multicolumn{3}{|l|}{ ECOG PS } \\
\hline 0 & 10 & 14.5 \\
\hline 1 & 40 & 57 \\
\hline 2 & 20 & 28.5 \\
\hline \multicolumn{3}{|c|}{ Number of metastatic sites } \\
\hline 1 & 17 & 24 \\
\hline 2 & 32 & 46 \\
\hline 3 & 21 & 30 \\
\hline \multicolumn{3}{|l|}{ Site of metastases } \\
\hline Liver & 48 & 68.5 \\
\hline Nodes & 41 & 58.5 \\
\hline Peritoneum & 41 & 58.5 \\
\hline Lung & 13 & 18.5 \\
\hline Bone & 6 & 8.5 \\
\hline \multicolumn{3}{|c|}{ PFS under first-line chemotherapy } \\
\hline$\geq 6$ months & 42 & 60 \\
\hline$<6$ months & 28 & 40 \\
\hline \multicolumn{3}{|c|}{ Chemotherapy-free interval } \\
\hline$>3$ months & 38 & 54 \\
\hline$<3$ months & 32 & 46 \\
\hline
\end{tabular}

Abbreviations: ECOG PS Eastern Cooperative Oncology Group Performance Status.

overall response rate (ORR) of $22.8 \%$ (95\% confidence interval (CI): 13.4-32.3). Stable disease (SD) was recorded in $21(30 \%)$ patients, translating into a disease control rate (DCR) of 52.8\%. Median PFS was 3.8 months (95\% CI: 3.3-4.4), and median OS was 6.2 months (95\% CI: 5.3-7.1) (Figure 1). In univariate analysis, the only significant predictors of OS were ECOG PS (0-1 vs 2: 7.0 months
Table 2 Response rate in $\mathbf{7 0}$ patients

\begin{tabular}{lcc}
\hline Responses & No. of patients & $\%$ \\
\hline Complete response & 1 & 1.4 \\
Partial response & 15 & 21.4 \\
Stable disease & 21 & 30 \\
Progressive disease & 33 & 47.2 \\
\hline
\end{tabular}

[95\% CI: 5.7-8.3] vs 5.0 months [95\%CI: 2.4-7.6], $P=0.01$; HR 1.94 [95\% CI: 1.13-3-33]) and PFS under first-line chemotherapy ( $\geq 6$ months vs $<6$ months: 7.1 months [95\% CI: 6.2-8.0] vs 4.0 months [95\% CI: 2.7-5.3], $\mathrm{p}=0.04$; HR 1.67 [95\% CI: 1.02-2.34]). We did not observe any significant difference in efficacy nor in PFS and OS between patients who received fluoropyrimidine in the first-line compared with patients who did not (ORR: $24.4 \%$ vs $20 \%$; PFS 3.8 vs 4.0 months, $P=0.79$; OS 6.2 vs 6.5 months, $P=0.61$ ).

\section{Toxicity}

Toxicities are listed in Table 3. A total of 352 cycles of FOLFIRI were analyzed in 70 patients, with a median of 6 cycles administered per patient (range, 2-12). The most common G3-4 toxicities were neutropenia (28.5\%) and diarrhea (14.5\%). Treatment discontinuation was necessary in 4 patients (5.7\%). A $50 \%$ dose reduction was required in 2 patients (2.8\%) for recurrent G3 diarrhea, whereas a $25 \%$ dose reduction was needed in 11 patients (21.2\%), mostly correlated with G3 diarrhea (7 patients). Five patients required granulocyte colony-stimulating factor (G-CSF) for G4 neutropenia.

\section{Discussion}

In the present study, we reported that the use of FOLFIRI in the second-line setting in docetaxel-pretreated metastatic gastric cancer is associated with an ORR of $22.8 \%$ and a DCR of $52.8 \%$. Median PFS and OS were 3.8 months and 6.2 months, respectively. To our knowledge, this is one of the largest series presented so far with second-line chemotherapy combination in non-Asian patients.

In the second-line setting, only two recent studies exploring the benefit of palliative chemotherapy were presented in full text. The Arbeitsgemeinschaft Internistische Onkologie (AIO) conducted in Germany analyzed single agent irinotecan $\left(250 \mathrm{mg} / \mathrm{m}^{2}\right.$ every 3 weeks, increased to $350 \mathrm{mg} / \mathrm{m}^{2}$ after the first cycle depending on toxicity) versus BSC [12]. Primary endpoint was OS. Even though the hazard ratio for death was 0.48 (95\% CI 0.25-0.92), results must be interpreted with caution. Only 40 patients of the preplanned 120 entered the study, which closed prematurely due to poor accrual. Regarding efficacy, no objective tumor responses were documented, and disease stabilization for at least 6 weeks was reported in 53\% of patients. 
A

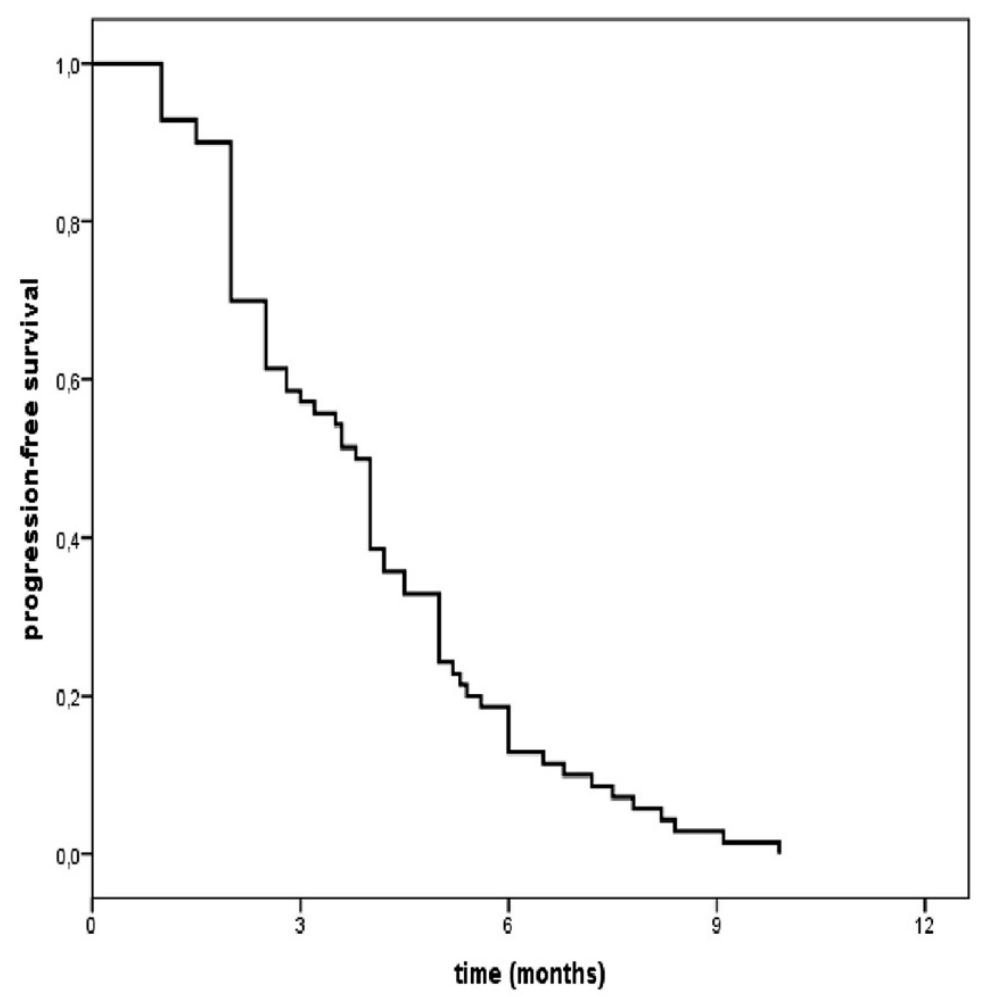

B

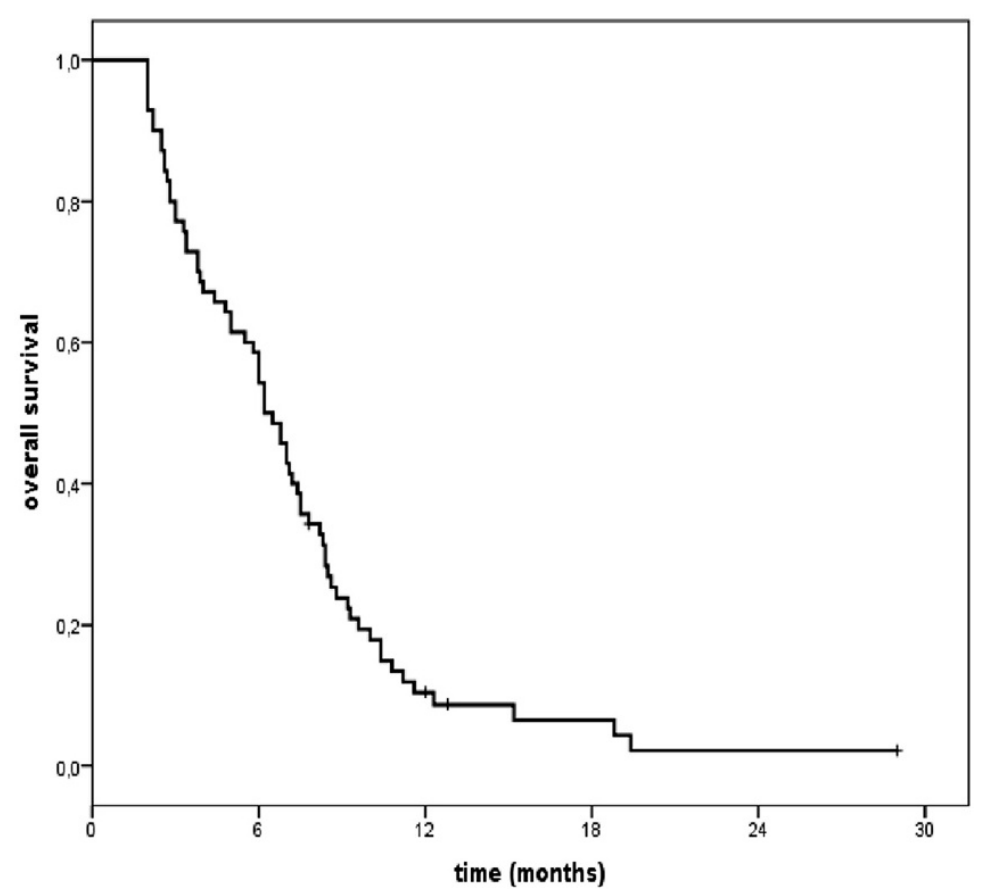

Figure 1 Kaplan-Meier curves. (A) progression-free survival. (B) overall survival. 
Table 3 Main toxicity in $\mathbf{7 0}$ patients

\begin{tabular}{lcc}
\hline Toxicity & Grade $\mathbf{3}(\%)$ & Grade 4 (\%) \\
\hline Neutropenia $^{\mathrm{a}}$ & 21.5 & 7 \\
Anemia & 7 & - \\
Thrombocytopenia & 3 & - \\
Diarrhea & 13 & 1.4 \\
Nausea/vomiting & 6 & - \\
Mucositis & 6 & - \\
Fatigue & 6 & - \\
Hepatotoxicity & 3 & - \\
\hline
\end{tabular}

${ }^{\mathrm{a}}$ Four episodes of febrile neutropenia in 3 patients (4\%).

We are aware of the intrinsic limitations of both retrospective studies and indirect comparisons. In our study, patient characteristics were similar, with the exception that in the AIO study none of the patients allocated in the irinotecan arm received docetaxel in first-line. However, even though the DCR was similar (52.8\% vs 53\%), we reported an ORR of $22.8 \%$. Apparently, FOLFIRI compares favorably when considering PFS (3.8 months vs 2.5 months) and OS (6.2 months vs 4.0 months). Surprisingly, FOLFIRI seemed to be better tolerated than irinotecan monotherapy (G3-4 diarrhea $14.4 \%$ vs $26 \%$, neutropenic fever $4 \%$ vs $16 \%$ ), probably because of the lower irinotecan cumulative dose and the different schedule.

In the second phase III trial, 202 Korean patients were randomized in a 2:1 fashion to receive either chemotherapy, consisting in biweekly irinotecan $150 \mathrm{mg} / \mathrm{m}^{2}$ or docetaxel $60 \mathrm{mg} / \mathrm{m}^{2}$ every 3 weeks at the physician's discretion, or BSC [13]. Docetaxel-containing chemotherapy was administered only in the $3 \%$ of patients. The intention to treat analysis showed an increase in OS with chemotherapy (5.3 months vs 3.8 months) with a HR of 0.657 (95\% CI: $0.485-0.891, P=0.007)$. No differences were seen in correlation with the type of chemotherapeutic agent, thus complementing the results from the Japanese phase III WJOG4007 study (reported only in abstract form) and from an European, randomized, three-arm phase II study which also evaluated a liposomal nanocarrier formulation of irinotecan $[19,20]$. Even though these results have to be considered as a major step forward in the management of gastric cancer, we believe they cannot be broadly generalized. It is known that the topographic distribution (distal vs proximal), pathological features (intestinal vs diffuse) and, even more importantly, survival outcome differ between Asian and Western patients $[14,21,22]$. Treatment pattern is one of the factors proposed to explain such discrepancies, as extensive D2 resection in early stage gastric cancer is routinely used in Asian countries. Nevertheless, a comparison of surgical outcomes between patients treated at the Memorial Sloan Kettering Cancer Center, where D2 resection is extensively carried out, and patients treated in Korea revealed better disease-specific survival for the latter group [23]. Therefore, it is foreseeable that underlying biological differences play a crucial role, and growing evidence indicate that the molecular taxonomy of gastric cancer is influenced by ethnic factors. MicroRNA expression profiling, which is emerging as an excellent classifier in oncology, and next-generation sequencing studies are beginning to unveil the existence of different sets of deregulated gene networks potentially correlated with ethnicity [24-26]. Furthermore, the molecular analysis of the ToGA trial revealed that HER2 positivity is associated with the intestinal-type gastric cancer (32.5\% intestinal vs $6.0 \%$ diffuse), the most common histology in Asia [8]. Overall, the different ethnicity-related molecular landscape of gastric cancer might reflect a different expression of therapeutic targets and, in turn, sensitivity to anticancer agents. Beyond tumor biology, also pharmacogenomic differences should be taken into account. For instance, while $\mathrm{S} 1$ is extensively used in front-line in Asia, its use in the Western hemisphere was initially constrained by evidence of more severe toxicity in Caucasian patients [27]. The different magnitude of toxic effects is thought to be correlated with CYP2A6 gene polymorphisms, affecting the conversion of S1 to fluorouracil. Indeed, in the phase III FLAG study conducted in non-Asian countries S1 was used at a lower dose compared to Japanese studies [28], despite the higher body surface of Western patients.

Next, in the European FFCD-GERCOR-FNCLCC trial 416 patients were randomized to receive two different sequential strategies in first- and second-line: epirubicin, cisplatin and capecitabine in first-line and FOLFIRI in second-line vs the reverse sequence [29]. The sequence with FOLFIRI in firstline resulted superior for the primary endpoint (time to treatment failure), a benefit deriving from the better tolerance and the correlated lower rate of treatment discontinuation. However, no firm conclusions can be drawn from this trial having been only presented in abstract form to date.

Finally, a recent retrospective Turkish study reported data from 97 docetaxel-pretreated patients who received FOLFIRI in the second-line setting [30]. Investigators reported an ORR of $26.8 \%$ and a DCR of $58.8 \%$. However, it is worth considering that 19 patients (19.5\%) had locally recurrent gastric cancer and 47 patients (48.5\%) had only one metastatic site. In our opinion, the rather heterogeneous study cohort along with the inclusion of a consistent fraction of patients with lower tumor burden compared to those examined in our study led to an overestimation of the results, as investigators reported a median OS of 10.5 months.

\section{Conclusions}

FOLFIRI appears an effective and safe treatment option for pretreated metastatic gastric cancer patients. However, second-line chemotherapy comparative trials are needed to better define the role of FOLFIRI in gastric cancer (e.g. versus monochemotherapy). 


\section{Competing interests}

The authors declared that they have no competing interests.

\section{Authors' contributions}

LDL and MM-S conceived and designed the study, LP, DS, MB, FB, SIF, AA, SB and PV collected and assembled the data, DG performed the statistical analysis, MM-S and LDL wrote the manuscript. All authors read and approved the final manuscript.

\section{Acknowledgements}

We thank Tania Merlino for technical assistance.

\section{Author details}

'Division of Medical Oncology B, "Regina Elena" National Cancer Institute, Via Elio Chianesi, 5300144 Rome, Italy. "Scientific Direction, "Regina Elena" National Cancer Institute, Via Elio Chianesi, 5300144 Rome, Italy. ${ }^{3}$ Division of Oncology, Spolverini Hospital, Ariccia, Italy. ${ }^{4}$ Division of Oncology, Fiorini Hospital, Terracina, Italy. ${ }^{5}$ Division of Biostatistics, "Regina Elena" National Cancer Institute, Via Elio Chianesi, 5300144 Rome, Italy. ${ }^{6}$ Sant'Andrea Hospital, Via di Grottarossa, 103500189 Rome, Italy.

\section{Received: 9 August 2013 Accepted: 16 September 2013}

Published: 17 September 2013

\section{References}

1. Jemal A, Bray F, Center MM, Ferlay J, Ward E, Forman D: Global cancer statistics. CA Cancer J Clin 2011, 61:69-90.

2. Cervantes A, Roda D, Tarazona N, Roselló S, Pérez-Fidalgo JA: Current questions for the treatment of advanced gastric cancer. Cancer Treat Rev 2013, 39:60-67.

3. Glimelius B, Ekström K, Hoffman K, Graf W, Sjödén PO, Haglund U, Svensson C, Enander LK, Linné T, Sellström H, Heuman R: Randomized comparison between chemotherapy plus best supportive care with best supportive care in advanced gastric cancer. Ann Oncol 1997, 8:163-168.

4. Murad AM, Santiago FF, Petroianu A, Rocha PR, Rodrigues MA, Rausch M: Modified therapy with 5-fluorouracil, doxorubicin, and methotrexate in advanced gastric cancer. Cancer 1993, 72:37-41.

5. Pyrhönen S, Kuitunen T, Nyandoto P, Kouri M: Randomised comparison of fluorouracil, epidoxorubicin and methotrexate (FEMTX) plus supportive care with supportive care alone in patients with non-resectable gastric cancer. Br J Cancer 1995, 71:587-591.

6. Van Cutsem E, Moiseyenko VM, Tjulandin S, Majlis A, Constenla M, Boni C, Rodrigues A, Fodor M, Chao Y, Voznyi E, Risse ML, Ajani JA: V325 Study Group. Phase III study of docetaxel and cisplatin plus fluorouracil compared with cisplatin and fluorouracil as first-line therapy for advanced gastric cancer: a report of the V325 Study Group. J Clin Oncol 2006, 24:4991-4997.

7. Koizumi W, Narahara H, Hara T, Takagane A, Akiya T, Takagi M, Miyashita K, Nishizaki T, Kobayashi O, Takiyama W, Toh Y, Nagaie T, Takagi S, Yamamura Y, Yanaoka K, Orita H, Takeuchi M: S-1 plus cisplatin versus S-1 alone for first-line treatment of advanced gastric cancer (SPIRITS trial): a phase III trial. Lancet Oncol 2008, 9:215-221.

8. Bang YJ, Van Cutsem E, Feyereislova A, Chung HC, Shen L, Sawaki A, Lordick F, Ohtsu A, Omuro Y, Satoh T, Aprile G, Kulikov E, Hill J, Lehle M, Rüschoff J, Kang YK, ToGA Trial Investigators: Trastuzumab in combination with chemotherapy versus chemotherapy alone for treatment of HER2positive advanced gastric or gastro-oesophageal junction cancer (ToGA): a phase 3, open-label, randomised controlled trial. Lancet 2010, 376:687-697.

9. Cunningham D, Starling N, Rao S, Iveson T, Nicolson M, Coxon F, Middleton G, Daniel F, Oates J, Norman AR, Upper Gastrointestinal Clinical Studies Group of the National Cancer Research Institute of the United Kingdom: Capecitabine and oxaliplatin for advanced esofagogastric cancer. N Eng J Med 2008, 358:36-46.

10. Al-Batran SE, Hartmann JT, Probst S, Schmalenberg H, Hollerbach S, Hofheinz R, Rethwisch V, Seipelt G, Homann N, Wilhelm G, Schuch G, Stoehlmacher J, Derigs HG, Hegewisch-Becker S, Grossmann J, Pauligk C, Atmaca A, Bokemeyer C, Knuth A, Jäger E: Phase III trial in metastatic gastroesophageal adenocarcinoma with fluouracil, leucovorin plus either oxaliplatin or cisplatin: a study of the arbeitgemeinschaft internistische onkologie. J Clin Oncol 2008, 26:1435-1442.
11. Bouché $O$, Raoul JL, Bonnetain F, Giovannini M, Etienne $P L$, Lledo $G$, Arsène D, Paitel JF, Guérin-Meyer V, Mitry E, Buecher B, Kaminsky MC, Seitz JF, Rougier P, Bedenne L, Milan C: Randomized multicenter phase II trial of a biweekly regimen of fluouracil and leucovorin (LV5FU2), LV5FU2 plus cisplatin, or LV5FU2 plus irinotecan in patients with previously untreated metastatic gastric cancer: a Fédération Francophone de Cáncerologie Digestive Group Study - FFCD 9803. J Clin Oncol 2004, 22:4319-4328.

12. Thuss-Patience $P$, Kretzschmar A, Bichev D, Deist T, Hinke A, Breithaupt $K$, Dogan Y, Gebauer B, Schumacher G, Reichardt P: Survival advantage for irinotecan versus best supportive care as second-line chemotherapy in gastric cancer - a randomized phase III study of the Arbeitgemeinschaft Internische Onkologie (AIO). Eur J Cancer 2011, 15:2306-2314.

13. Kang JH, Lee SI, Lim DH, Park KW, Oh SY, Kwon HC, Hwang IG, Lee SC, Nam E, Shin DB, Lee J, Park JO, Park YS, Lim HY, Kang WK, Park SH: Salvage chemotherapy for pretreated gastric cancer: a randomized phase III trial comparing chemotherapy plus best supportive care with best supportive care alone. J Clin Oncol 2012, 30:1513-1518.

14. Kim R, Tan A, Choi M, El-Rayes BF: Geographic differences in approach to advanced gastric cancer: Is there a standard approach? Crit Rev Oncol Hematol 2013: doi: 10.1016/j.critrevonc.2013.05.007. [Epub ahead of print].

15. Di Lauro L, Sergi D, Belli F, Fattoruso SI, Arena MG, Pizzuti L, Vici P. Docetaxel, oxaliplatin, and capecitabine (DOX) combination chemotherapy for metastatic gastric or gastroesophageal junction (GEJ) adenocarcinoma [abstract ]. J Clin Oncol 2013, 31(Suppl):e15065.

16. Di Lauro L, Belli F, Arena MG, Carpano S, Paoletti G, Giannarelli D, Lopez M: Epirubicin, cisplatin and docetaxel combination therapy for metastatic gastric cancer. Ann Oncol 2005, 16:1498-1502.

17. Di Lauro L, Giacinti L, Arena MG, Sergi D, Fattoruso SI, Giannarelli D, Lopez M: Phase II study of epirubicin, oxaliplatin and docetaxel combination in metastatic gastric or gastroesophageal junction adenocarcinoma. $J$ Exp Clin Cancer Res 2009, 28:34.

18. Roth AD, Maibach R, Martinelli G, Fazio N, Aapro MS, Pagani O, Morant R, Borner MM, Herrmann R, Honegger H, Cavalli F, Alberto P, Castiglione M, Goldhirsch A: Docetaxel (Taxotere)-cisplatin (TC): an effective drug combination in gastric carcinoma. Swiss Group for Clinical Cancer Research (SAKK), and the European Institute of Oncology (EIO). Ann Oncol 2000, 11:301-306

19. Ueda S, Hironaka S, Yasui H, Nishina T, Tsuda M, Tsumura T, Sugimoto N, Shimodaira H, Tokunaga S, Moriwaki T, Esaki T, Nagase M, Fujitani K, Yamaguchi K, Ura T, Hamamoto Y, Morita S, Okamoto I, Boku N, Hyodo I: Randomized phase III study or irinotecan (CPT-11) versus weekly paclitaxel (WPTX) fir advanced gastric cancer (AGC) refractory to combination chemotherapy (CT) of fluoropyrimidine plus platinum (FP): WJOG4007 [abstract ]. J Clin Oncol 2012, 30(Suppl):4002.

20. Roy AC, Park SR, Cunningham D, Kang YK, Chao Y, Chen LT, Rees C, Lim HY, Tabernero J, Ramos FJ, Kujundzic M, Cardic MB, Yeh CG, de Gramont A: A randomized phase II study of PEP02 (MM-398), irinotecan or docetaxel as a second-line therapy in patients with locally advanced or metastatic gastric or gastro-oesophageal junction adenocarcinoma. Ann Oncol 2013, 24:1567-1573

21. Ito H, Inoue H, Ikeda H, Onimaru M, Yoshida A, Hosoya T, Sudo K, Eleftheriadis N, Maselli R, Maeda C, Wada Y, Sando N, Hamatani S, Kudo SE: Clinicopathological characteristics and treatment strategies in early gastric cancer: a retrospective cohort study. J Exp Clin Cancer Res 2011 30:117.

22. Ito H, Inoue H, Odaka N, Satodate H, Suzuki M, Mukai S, Takehara Y, Kida H, Kudo SE: Clinicopathological characteristics and optimal management for esophagogastric junctional cancer; a single center retrospective cohort study. J Exp Clin Cancer Res 2013, 32:2.

23. Strong VE, Song KY, Park CH, Jacks LM, Gonen M, Shah M, Coit DG, Brennan MF: Comparison of gastric cancer survival following RO resection in the United States and Korea using an internationally validated nomogram. Ann Surg 2010, 251:640-646.

24. Volinia S, Calin GA, Liu CG, Ambs S, Cimmino A, Petrocca F, Visone R, lorio M, Roldo C, Ferracin M, Prueitt RL, Yanaihara N, Lanza G, Scarpa A, Vecchione A, Negrini M, Harris CC, Croce CM: A microRNA expression signature of human solid tumors defines cancer gene targets. Proc Natl Acad Sci U S A 2006, 103:2257-2261.

25. Ueda T, Volinia S, Okumura H, Shimizu M, Taccioli C, Rossi S, Alder H, Liu CG, Oue N, Yasui W, Yoshida K, Sasaki H, Nomura S, Seto Y, Kaminishi M, Calin GA, Croce CM: Relation between microRNA expression and progression and 
prognosis of gastric cancer: a microRNA expression analysis. Lancet Oncol 2010, 11:136-146.

26. Liang $\mathrm{H}$, Kim YH: Identifying molecular drivers of gastric cancer through next-generation sequencing. Cancer Lett: doi: 10.1016/j.canlet.2012.11.029. [Epub ahead of print].

27. Ajani JA, Faust J, Ikeda K, Yao JC, Anbe H, Carr KL, Houghton M, Urrea P: Phase I pharmacokinetic study of S-1 plus cisplatin in patients with advanced gastric carcinoma. J Clin Oncol 2005, 23:6957-6965.

28. Ajani JA, Rodriguez W, Bodoky G, Moiseyenko V, Lichinitser M, Gorbunova V, Vynnychenko I, Garin A, Lang I, Falcon S: Multicenter phase III comparison of cisplatin/S-1 with cisplatin/infusional fluorouracil in advancedgastric or gastroesophageal adenocarcinoma study: the FLAGS trial. J Clin Oncol 2010, 28:1547-1553.

29. Guimbaud R, Louvet $C$, Bonnetain F, Viret F, Samalin E, Gornet JM, André T, Rebischung $\mathrm{C}$, Bouche $\mathrm{O}$, Jouve JL: Final results of the intergroup FFCDGERCOR-FNCLCC 03-07 phase III study comparing two sequences of chemotherapy in advanced gastric cancers [abstract ]. Ann Oncol 2010, 21(8):viii 250.

30. Kaya AO, Coskun U, Gumus M, Dane F, Ozkan M, Isıkdogan A, Alkis N, Buyukberber S, Yumuk F, Budakoglu B, Demirci U, Berk V, Bilici A, Inal A, Arpacı E, Benekli M, Anatolian Society of Medical Oncology (ASMO): The efficacy and toxicity of irinotecan with leucovorin and bolus and continuous infusional 5 -fluorouracil (FOLFIRI) as salvage therapy for patients with advanced gastric cancer previously treated with platinum and taxane-based chemotherapy regimens. J Chemother 2012, 4:217-220.

doi:10.1186/1756-9966-32-67

Cite this article as: Maugeri-Saccà et al:: FOLFIRI as a second-line therapy in patients with docetaxel-pretreated gastric cancer: a historical cohort. Journal of Experimental \& Clinical Cancer Research 2013 32:67.

\section{Submit your next manuscript to BioMed Central and take full advantage of:}

- Convenient online submission

- Thorough peer review

- No space constraints or color figure charges

- Immediate publication on acceptance

- Inclusion in PubMed, CAS, Scopus and Google Scholar

- Research which is freely available for redistribution 